\title{
A young child with a headache
}

Wayne Liao, Douglas Thomas

\section{CASE}

A boy aged five years presented with a new recurrent headache over the past month, associated with nausea and occasional vomiting, as well as photophobia, phonophobia and pallor. The episodes lasted up to six hours at a time and occurred 3-4 times per week. They were usually preceded by approximately 30 minutes of irritable and dysregulated behaviour. They occurred at any time of the day. The patient had only woken up once with the headache. There was no abdominal pain.

The patient's history included atopic dermatitis and obstructive sleep apnoea successfully treated with tonsillectomy. He lived with his mother and sister and attended day care. His immunisations were up to date and he was developmentally appropriate. His mother reported experiencing classic migraines with aura.

\section{QUESTION 1}

What are the causes of recurrent headaches in children and adolescents?

\section{QUESTION 2}

What are the red flags on history and examination?

\section{ANSWER 1}

Primary headaches are the most common cause of recurrent headaches in children. ${ }^{1}$ The prevalence of paediatric migraines is high in Australia and increases with age, estimated to be roughly $4 \%$ in children aged $5-9$ years, $16 \%$ in those aged 10-14 years and $20 \%$ in adolescents aged 15-19 years. ${ }^{2}$ Other primary headaches include tension headaches and, less commonly, trigeminal autonomic cephalalgias such as cluster headaches. ${ }^{3}$

Secondary causes are less common in recurrent headaches. ${ }^{1}$ Potential causes are extensive and range from rare but sinister causes such as brain tumour and cerebral venous thrombosis, to other causes, including but not limited to medication overuse (eg nonsteroidal anti-inflammatory drugs [NSAIDs] and steroids), idiopathic raised intracranial hypertension, endocrine conditions, obstructive sleep apnoea, dental disease and psychiatric disorders. ${ }^{3}$

\section{ANSWER 2}

Box 1 outlines red flags compiled from various guidelines. ${ }^{3-10}$ Signs and symptoms may become progressively evident, and regular monitoring is paramount. ${ }^{6}$ Multiple red flags, and certain high-risk features such as associated seizures and focal neurological deficits, should be particularly alarming to clinicians and prompt further investigations. ${ }^{9,10}$

\section{CASE CONTINUED}

There were no red flags on further history. A complete neurological examination including cerebellar examination was normal except for some anisocoria, which the patient's mother reported was long standing and evident on old photographs. A formal review by an optometrist revealed normal retinae and no papilloedema.

The child was reviewed by a paediatrician, who confirmed the diagnosis of paediatric migraine. The headaches improved with conservative management without further investigation.

\section{QUESTION 3}

How should recurrent paediatric headaches be investigated?

QUESTION 4

How do paediatric migraines present differently to those in adults?

\section{QUESTION 5}

What is the management of paediatric migraines?

ANSWER 3

Neuroimaging is not routinely recommended in the absence of red flags, ${ }^{5}$ and unscrutinised use can risk incidental findings, harm from need for procedural sedation and over-reliance on imaging rather than careful clinical followup. ${ }^{10}$ If required, magnetic resonance imaging (MRI) is preferable to computed tomography because of its superiority in detecting posterior fossa pathology and lower radiation risk. ${ }^{6}$ Referral to an ophthalmologist or skilled optometrist can detect subtle signs of visual disturbance 
(Box 1). ${ }^{3,6}$ A lumbar puncture may be considered to measure opening pressure but is usually not required. ${ }^{3}$

In Australia, general practitioners can order MRI under Medicare Benefits Schedule rebates if a child aged $<16$ years has unexplained seizures or unexplained headaches with suspected significant pathology. ${ }^{11}$

\section{ANSWER 4}

Table 1 outlines the different symptomology of children when compared with adults. In adolescents (ie those aged $\geq 12$ years), the clinical manifestations become more similar. ${ }^{1}$ In addition, there are several migraine-related syndromes - including abdominal migraines, cyclic vomiting syndrome and benign paroxysmal torticollis - that are specifically relevant in children. ${ }^{12,13}$

\section{ANSWER 5}

Effective migraine management begins with educating the parent and child regarding the diagnosis. It is important to reassure parents regarding the absence of intracranial pathology and that effective multimodal treatment options exist. ${ }^{3}$

Acute attacks should be treated with ibuprofen as first line or paracetamol as second line, taken as soon as possible..$^{8,14}$ Aspirin should be avoided because of the rare risk of Reye's syndrome. ${ }^{14}$ Ondansetron

\section{Box 1. Red flag features of recurrent headaches suggesting} intracranial pathology $y^{3-10}$

\section{Features of headache}

- New (<6 months) and severe

- Escalating severity and frequency

- Persistently wakes the child from sleep or occurs on waking

- Change in character of pre-existing headache

\section{Associated neurological abnormalities}

- Visual disturbance, including changes in acuity, visual field or extraocular movements

- Abnormal fundoscopy findings such as papilloedema

- Motor abnormalities, including focal deficits, gait disturbance, loss of coordination and other cerebellar signs

\section{Other associations}

- Seizures

- Persistent vomiting on waking

- Changes in behaviour and personality

- Fever

- Known systemic comorbidity (eg rheumatological disorder, immunosuppression, malignancy, hypertension)

Age $<4$ years

Table 1. Symptomology of typical migraine attacks in children versus adults ${ }^{13}$

\begin{tabular}{lll}
\hline & Children & Adults \\
\hline Duration & $\begin{array}{l}\text { 2-72 hours; as short as } 30 \text { minutes } \\
\text { according to some authors }\end{array}$ & $4-72$ hours \\
\hline Site & Often bilateral & Usually unilateral \\
\hline $\begin{array}{l}\text { Photophobia and } \\
\text { phonophobia }\end{array}$ & $\begin{array}{l}\text { May need to be inferred from their } \\
\text { behaviour and often not verbalised }\end{array}$ & Often reported \\
\hline Aura & $\begin{array}{l}\text { Can occur; visual aura can be atypical } \\
\text { and bilateral }\end{array}$ & $\begin{array}{l}\text { Can occur; visual aura } \\
\text { usually unilateral }\end{array}$ \\
\hline
\end{tabular}

is the preferred treatment for nausea. Sumatriptan or rizatriptan can be used in children aged $\geq 6$ years. ${ }^{14}$ Rescue therapy should be limited to $<10-15$ days of NSAIDs and $<8$ days of triptans per month to prevent medication overuse headaches. ${ }^{3}$

Holistic long-term prophylactic management is paramount to prevent recurrent attacks, analgesia overuse and long-term morbidity. This should include addressing family factors and using lifestyle, psychological and pharmacological treatments. Familial and school stressors, communication issues and relationship conflicts should be considered, as they can negatively affect the child's migraine management. ${ }^{1,15}$

A headache diary can identify common triggers such as stress and sleep deprivation, as well as monitor response to treatment. ${ }^{3,8,16}$ Lifestyle modifications focus on avoiding dehydration and ensuring adequate sleep, consistent healthy diet and regular physical activity. ${ }^{3,15}$ Stress is a major contributor to migraines, and psychological therapies, especially cognitive behavioural therapy, have been shown to be effective. . $^{3,15}$

Pharmacological migraine prophylaxis should be reserved for disabling cases that occur more than 3-4 times per month. ${ }^{17,18}$ There is a limited number of studies that review prophylactic treatment in children, and some medications do not necessarily differ from placebo in efficacy while potentially causing more side effects. ${ }^{17}$ The side-effect burden relevant to the patient's comorbidities ${ }^{17}$ and the practitioner's experience should be considered when selecting a medication. ${ }^{18} \mathrm{~A}$ headache diary should be used concurrently to establish a change in symptom frequency and severity. Effective medications should be continued for 6-9 months prior to stopping slowly to establish if there is ongoing clinical indication. ${ }^{18}$

\section{Key points}

- Migraine is a highly prevalent cause of recurrent headaches in children and adolescents.

- Imaging is not routinely required after red flags have been excluded with a thorough history and examination. 
- Long-term management is multimodal and should focus on addressing familial, lifestyle and psychological factors, with prophylactic medications reserved for severe cases.

\section{Authors}

Wayne Liao MBBS, DCH, FRACGP, General Practitioner, MyHealth Wellington Point Family Practice, Qld; Senior Lecturer, School of Medicine, Griffith University, Qld

Douglas Thomas MBChB, FRACP, Director of Paediatrics, Redland Hospital and Wynnum Health Service, Metro South Health, Qld; Senior Lecturer, School of Clinical Medicine PAH - Southside Clinical Unit, Qld

Competing interests: None.

Funding: None.

Provenance and peer review: Not commissioned, externally peer reviewed.

\section{Correspondence to:}

w.liao@griffith.edu.au

\section{References}

1. Straube A, Heinen F, Ebinger F, von Kries R. Headache in school children: Prevalence and risk factors. Dtsch Arztebl Int 2013;110(48):811-18. doi: 10.3238/arztebl.2013.0811.

2. Deloitte Access Economics. Migraine in Australia white paper. Canberra, ACT: Deloitte Access Economics, 2018; p. 55.

3. Blume HK. Childhood headache: A brief review. Pediatr Ann 2017;46(4):e155-e65. doi: 10.3928/19382359-20170321-02.

4. Medina LS, Pinter JD, Zurakowski D, Davis RG, Kuban K, Barnes PD. Children with headache: Clinical predictors of surgical space-occupying lesions and the role of neuroimaging. Radiology 1997;202(3):819-24. doi: 10.1148/ radiology.202.3.9051039.

5. Lewis DW, Ashwal S, Dahl G, et al. Practice parameter: Evaluation of children and adolescents with recurrent headaches: Report of the Quality Standards Subcommittee of the American Academy of Neurology and the Practice Committee of the Child Neurology Society. Neurology 2002;59(4):490-98. doi: 10.1212/ wnl.59.4.490.

6. Kariyawasam DS, McShane T. Brain tumours in paediatrics: When should they be suspected? Arch Dis Child 2015;100(12):1102-03. doi: 10.1136/ archdischild-2015-308729.

7. Wilne S, Koller K, Collier J, Kennedy C, Grundy R, Walker $D$. The diagnosis of brain tumours in children: A guideline to assist healthcare professionals in the assessment of children who may have a brain tumour. Arch Dis Child 2010;95(7):534-39. doi: 10.1136/adc.2009.162057.

8. Oskoui M, Pringsheim T, Holler-Managan Y, et al. Practice guideline update summary: Acute treatment of migraine in children and adolescents: Report of the Guideline Development, Dissemination, and Implementation Subcommittee of the American Academy of Neurology and the American Headache Society. Headache 2019;59(8):1158-73. doi: 10.1111/ head.13628.

9. Rho YI, Chung HJ, Suh ES, et al. The role of neuroimaging in children and adolescents with recurrent headaches - Multicenter study. Headache 2011;51(3):403-08. doi: 10.1111/j.15264610.2011.01845.x

10. Roser $T$, Bonfert $M$, Ebinger $F$, Blankenburg $M$ Ertl-Wagner B, Heinen F. Primary versus secondary headache in children: $A$ frequent diagnostic challenge in clinical routine. Neuropediatrics 2013;44(1):34-39. doi: 10.1055/s0032-1332743.

11. Department of Health. Improving access to magnetic resonance imaging (MRI) services fact sheet. Canberra, ACT: DoH. Available at www1. health.gov.au/internet/main/publishing.nsf/ Content/di-factsheet-mri [Accessed 8 August 2020].

12. Straube A, Andreou A. Primary headaches during lifespan. J Headache Pain 2019;20(1):35. doi: 10.1186/s10194-019-0985-0.

13. Headache Classification Committee of the International Headache Society (IHS). The international classification of headache disorders, 3rd edn. Cephalalgia 2018;38(1):1-211. doi: 10.1177/0333102417738202.

14. Expert Group for Migraine. Migraine in children. In eTG complete [Internet]. West Melbourne, Vic: Therapeutic Guidelines Limited, 2017.

15. Kroon Van Diest AM, Ernst MM, Slater S, Powers SW. Similarities and differences between migraine in children and adults: Presentation, disability, and response to treatment. Curr Pain Headache Rep 2017;21(12):48. doi: 10.1007/s11916017-0648-2

16. Neut D, Fily A, Cuvellier JC, Vallee L. The prevalence of triggers in paediatric migraine: A questionnaire study in 102 children and adolescents. J Headache Pain 2012;13(1):61-65 doi: 10.1007/s10194-011-0397-2.

17. Papetti L, Ursitti F, Moavero R, et al. Prophylactic treatment of pediatric migraine: Is there anything new in the last decade? Front Neurol 2019;10:771. doi: 10.3389/fneur.2019.00771.

18. Metro South Health. SpotOnHealth HealthPathways. Brisbane, Qld: Queensland Government, 2018. Available at https:// metrosouth.health.qld.gov.au/spotonhealthhealthpathways [Accessed 8 August 2020].

19. Özge A, Faedda N, Abu-Arafeh I, et al. Experts' opnion about the primary headache diagnostic criteria of the ICHD-3rd edition beta in children and adolescents. J Headache Pain 2017;18(1):109. doi: 10.1186/s10194-017-0818-y. 